\title{
PRSS1 intron mutations in patients with pancreatic cancer and chronic pancreatitis
}

\author{
FENG GAO $^{1}$, QI-CAI LIU ${ }^{2,5}$, SHENG ZHANG ${ }^{1}$, ZE-HAO ZHUANG $^{3}$, CAI-ZHU LIN $^{4}$ and XIN-HUA LIN ${ }^{6}$ \\ Departments of ${ }^{1}$ Pathology, ${ }^{2}$ Laboratory Medicine, ${ }^{3}$ Gastroenteropathy, and ${ }^{4}$ Anesthesiology, \\ The First Affiliated Hospital, Fujian Medical University, Fuzhou 350005; \\ Departments of ${ }^{5}$ Gene Diagnosis, and ${ }^{6}$ Pharmaceutical Analysis, \\ Fujian Medical University, Fuzhou 350005, P.R. China
}

Received June 6, 2011; Accepted November 14, 2011

DOI: $10.3892 / \mathrm{mmr} .2011 .684$

\begin{abstract}
Genetic risk factors of chronic pancreatitis (CP) have been identified and a number of studies have found that $\mathrm{CP}$ can lead to pancreatic cancer. Therefore, the detection of pancreatitis-associated gene mutations can aid the pancreatic cancer diagnostic process. Mutations in three genes, the cationic trypsinogen (PRSS1) gene, the cystic fibrosis transmembrane conductance regulator $(C F T R)$ gene and the pancreatic secretory trypsin inhibitor (SPINK1) gene, have been identified as risk factors for CP. The aim of this study was to describe specific novel mutations in the intron of the PRSS1 gene in patients with pancreatic cancer and CP. A total of 65 unrelated patients with pancreatic cancer and 29 with CP were reviewed. Mutations and polymorphisms of the PRSS1 gene were analyzed by direct sequencing. Information regarding clinical data and smoking exposure was collected by personal interviews using a structured questionnaire. IVS $3+36 \mathrm{~A}>\mathrm{G}$ mutation in the PRSS1 gene was found in 2 cases with pancreatic cancer, and these 2 patients were classified as never-smokers. IVS $3+127 \mathrm{~T}>\mathrm{A}$ and IVS $3+157 \mathrm{G}>\mathrm{C}$ double mutations were identified in one patient with CP. All patients were found to have serum trypsin levels lower than that of the normal controls. Therefore, the PRSS1 gene mutation may be a special common cause of pancreatic cancer and CP.
\end{abstract}

\section{Introduction}

Chronic pancreatitis (CP) tends to be a precurser to pancreatic cancer (1-5). This observation is striking in hereditary pancreatitis kindreds but also occurs in alcoholic, idiopathic and tropical $\mathrm{CP}$, as well as cystic fibrosis. The mutations

Correspondence to: Dr Cai-Zhu Lin, Department of Anesthesiology, The First Affiliated Hospital, Fujian Medical University, Fuzhou 350005, P.R. China

E-mail: fymzk6822@163.com

Key words: pancreatic cancer, chronic pancreatitis, PRSS1 gene, mutations
$R 122 H$ and $N 29 I$ of the PRSS1 gene, as well as the variant $C 139 S$, appear to result in a 53-fold increased incidence of pancreatic ductal adenocarcinoma (PDAC) (6-8). This suggests that the high risk of pancreatic adenocarcinoma in patients with $\mathrm{CP}$ is due to an accelerated process of mutagenesis and mutation accumulation rather than a unique process $(9,10)$.

\section{Patients and methods}

Patient recruitment and data collection. In the prevous 6 years, 65 unrelated patients (45 males and 20 females) with pancreatic cancer and 29 cases (19 males and 10 females) with $\mathrm{CP}$ were investigated. To identify etiological patterns in this Chinese cohort of patients, clinical features, and biogenetic and pathological examination were evaluated, retrospectively.

Diagnosis was based on both the clinical presentation, as well as the characteristic pathological findings, and detected by using computed tomography (CT) scan or magnetic resonance imaging (MRI).

DNA extraction and genotype analysis. Genomic DNA was extracted from the peripheral blood of specimens using a QIAamp DNA mini kit (Qiagen, Hilden, Germany). The entire sequence of the PRSS1 gene was examined by polymerase chain reaction (PCR), and direct sequencing was carried out. The four primer pairs covered the whole sequence of the PRSS1 gene, and experimental conditions used to generate four fragments were used as references $(10,11)$. For sequencing, a Perkin Elmer Big Dye Sequencing kit and an ABI PRISM7700 sequencer were used.

Exposure and clinical data collection. Information on demographics and smoking exposure was collected by carrying out personal interviews using a structured questionnaire. The participants were classified as ever-smokers or never-smokers according to whether they had ever smoked $>100$ cigarettes in their lifetime. Cumulative smoking exposure was estimated in pack-years, which were based on the average daily cigarette intake and the number of years smoked. All of the clinical data were collected at the same time, and all studies were performed after the informed consent of patients was obtained. 
A $\downarrow$

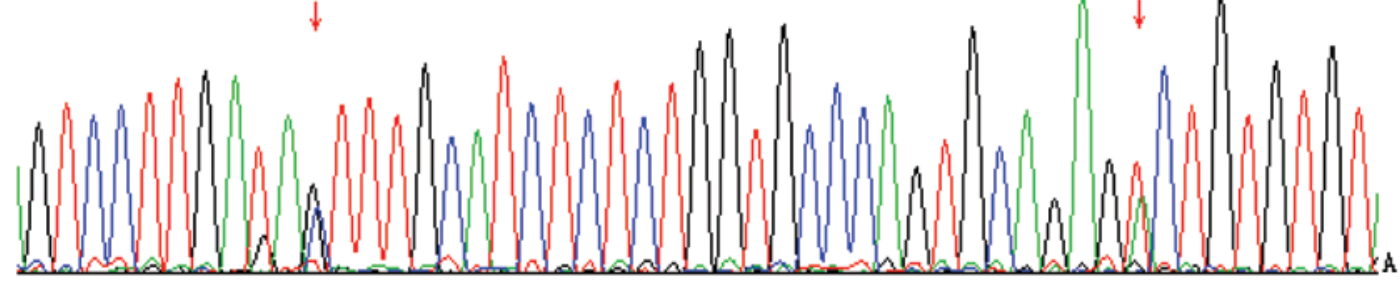

B

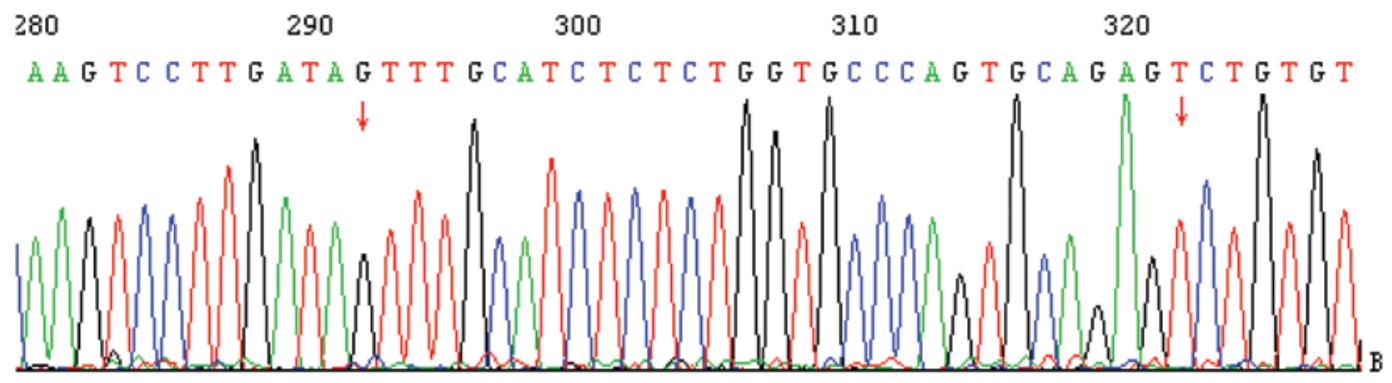

Figure 1. IVS $3+127 \mathrm{~T}>\mathrm{A}$ and IVS $3+157 \mathrm{G}>\mathrm{C}$ double mutations of the PRSS1 gene. (A) Sequence of the PRSS1 gene from blood sample of a patient with pancreatic cancer. (B) The sequence of a normal control.

\section{Results}

IVS $3+127 \mathrm{~T}>\mathrm{A}$ and IVS $3+157 \mathrm{G}>\mathrm{C}$ mutations in the PRSSI gene were discovered in a subject with CP (Fig. 1), and one pancreatic cancer patient had an IVS $3+36 \mathrm{~A}>\mathrm{G}$ mutation (Fig. 2). Both of the patients were elderly men and were admitted to the First Affiliated Hospital, Fujian Medical University, China, with a history of jaundice and steatorrhea. Biochemical testing revealed diabetes mellitus (in the latest World Health Organization and Second Giessen International Workshop on Interactions of Exocrine and Endocrine Pancreatic Diseases classification of diabetes, pancreatic diabetes is classified as type 3c) (12). Serum trypsin (R\&D; American) of these patients was significantly lower than that of the other patients and normal controls.

\section{Discussion}

According to recent estimations, genetic alterations may be regarded as more severe risk factors than chronic alcohol consumption for CP. However, $\mathrm{CP}$ is often a precursor to pancreatic cancer (5). Therefore, in our department, genetic screening is offered to all patients with pancreatitis. Pancreatic inflammation appears to increase the risk of pancreatic cancer, suggesting that the effects are indirect by causing recurrent pancreatitis and chronic inflammation. The process of mutation accumulation and clonal expansion that is required for development of invasive pancreatic adenocarcinoma should therefore be accelerated in CP to account for the high incidence of pancreatic cancer in these patients. The analysis of gene mutations and gene expression in pancreatic cancer and $\mathrm{CP}$ has identified several factors that are similarly de-regulated in both diseases. Thus, it is of major importance to identify genetic markers that help to stratify the risk of malignant transformation in CP (12-14).

The pathway between inflammation and cancer involves numerous steps and converging risk factors. The primary
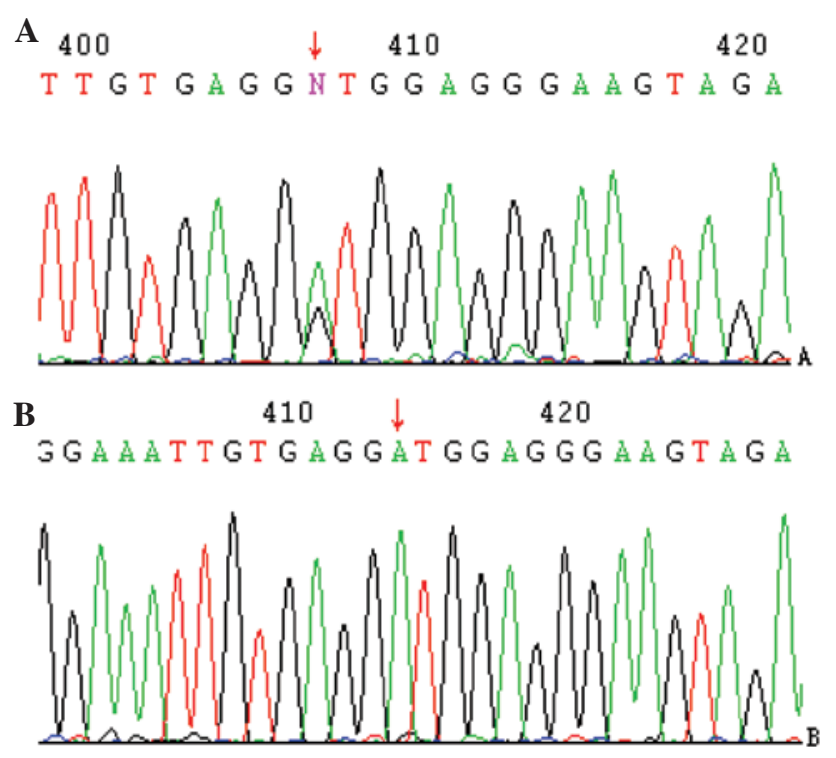

Figure 2. IVS $3+36 \mathrm{~A}>\mathrm{G}$ mutation of the PRSS1 gene. (A) The sequence results of a complicated mutation. (B) The sequencing of a normal control.

pathway, if there is one, remains an area of research and controversy. However, certain aspects of this pathway are becoming clearer as new data and perspectives are being formulated. The first point is that pancreatic adenocarcinoma is a genetic disorder of pancreatic parenchymal cells and that a general pattern of progressive accumulation of mutations is usually recognized. This pattern has been organized into the Pancreatic Intraepithelial Neoplasm (PanIN) system $(5,15,16)$. A complex trait or disorder is a condition that is caused by two or more factors (e.g., gene-gene or gene-environmental interactions) and therefore represents a genetic disorder that does not strictly follow Mendelian inheritance patterns. For reasons that are not yet clear, trypsin is closely related to 
the immune mechanism, and trypsin deficiency may lead to the activation of other blocked enzymes, as well as microenvironmental changes in pancreatic cells. In the context of chronic inflammation, the pancreatic parenchymal cells are exposed to growth and proliferative factors plus agents that can cause DNA damage. Smoking probably exaggerates this process. Trypsin may contribute to the continuous stimulation of cancer cell proliferation by activating PAR-2 (17-18).

Clearly, the data basis for the estimation of the pancreatic cancer risk in the patients with PRSSI-associated CP is small. At present, there is no generally accepted protocol for screening CP patients for early pancreatic cancer. However, affected mutation carriers should be strongly advised to stop smoking, as it is an additional risk factor for pancreatic cancer.

\section{Acknowledgements}

The present study was financially supported by the Project Foundation of Fujian Provincial Education (JA10143), the National High Technology Investigation Project Foundation of China (2008AA02Z433), the National Natural Science Foundation of China (20975021 and 20805006) and the Major Program Foundation of Fujian Medical University (09ZD013).

\section{References}

1. Farrow B and Evers BM: Inflammation and the development of pancreatic cancer. Surg Oncol 10: 153-169, 2002.

2. Hengstler JG, Bauer A, Wolf HK, Bulitta CJ, Tanner B, Oesch F, Gebhard S and Boettger T: Mutation analysis of the cationic trypsinogen gene in patients with pancreatic cancer. Anticancer Res 20: 2967-2974, 2000.

3. Howes N, Lerch MM, Greenhalf W, Stocken DD, Ellis I, Simon P, Truninger K, Ammann R, Cavallini G, Charnley R, Uomo G, Delhaye M, Spicak J, Drumm B, Jansen J, Mountford R, Whitcomb DC and Neoptolemos JP: Clinical and genetic characteristics of hereditary pancreatitis in Europe. Clin Gastroenterol 2: 252-261, 2004.

4. Hruban RH, Adsay NV, Albores-Saavedra J, Compton C, Garrett ES, Goodman SN, Kern SE, Klimstra DS, Kloppel G, Longnecker DS, Luttges J and Offerhaus GJ: Pancreatic intraepithelial neoplasia: a new nomenclature and classification system for pancreatic duct lesions. Am J Surg Pathol 25: 579-586, 2001.

5. Lowenfels AB, Maisonneuve P, Dimagno EP, et al: Hereditary pancreatitis and the risk of pancreatic cancer. International Hereditary Pancreatitis Study Group. J Natl Cancer Inst 89: 442-446, 1997.
6. Whitcomb DC and Pogue-Geile K: Pancreatitis as a risk for pancreatic cancer. Gastroenterol Clin North Am 31: 663-678, 2002.

7. Jemal A, Siegel R, Ward E, Hao YP, Xu JQ, Murray T and Thun M: Cancer statistics 2008. CA Cancer J Clin 58: 71-96, 2008.

8. Liu QC, Gao F, Ou QS, Zhuang ZH, Yang B and Lin SR: Novel mutation and polymorphism of PRSS1 gene in the Chinese patients with hereditary pancreatitis and chronic pancreatitis. Chin Med J 121: 108-111, 2008.

9. Lowenfels AB, Maisonneuve P, Cavallini G, Ammann RW, Lankisch PG, Andersen JR, Dimagno EP, Andren SA and Domellof L: Pancreatitis and the risk of pancreatic cancer. N Engl J Med 328: 1433-1437, 1993.

10. Chen JM and Férec C: Chronic pancreatitis: genetics and pathogenesis. Annu Rev Genomics Hum Genet 10: 63-87, 2009.

11. Grocock CJ, Rebours V, Delhaye M, Andren-Sandberg A, Weiss FU, Mountford R, Harcus M, Levy P, Lerch MM and Greenhalf W: European Registry of Hereditary Pancreatitis and Pancreatic Cancer. The variable phenotype of the p.A16V mutation of cationic trypsinogen (PRSS1) in pancreatitis families. Gut 59: 357-363, 2010.

12. Liu QC, Zhuang ZH, Zeng K, Cheng ZJ, Gao F and Wang ZQ. Prevalence of pancreatic diabetes in patients carrying mutations or polymorphisms of the PRSS1 gene in the Han population. Diabetes Technol Ther 11: 799-804, 2009.

13. Kinzler KW and Vogelstein B: Landscaping the cancer terrain. Science 280: 1036-1037, 1998.

14. Lowenfels AB, Maisonneuve P, Whitcomb DC, Lerch MM and DiMagno EP: Cigarette smoking as a risk factor for pancreatic cancer in patients with hereditary pancreatitis. JAMA 286: 169-170, 2001.

15. Friess H, Ding J, Kleeff J, et al: Identification of disease-specific genes in chronic pancreatitis using DNA array technology. Ann Surg 234: 769-778, 2001.

16. Talamini G, Falconi M, Bassi C, et al: Incidence of cancer in the course of chronic pancreatitis. Am J Gastroenterol 94: 1253-1260, 1999.

17. Tang Z, Geng G, Huang Q, Xu G, Hu H, Chen J and Li J: Prognostic significance of tissue factor pathway inhibitor- 2 in pancreatic carcinoma and its effect on tumor invasion and metastasis. Med Oncol 27: 867-875, 2010.

18. Caruso R, Pallone F, Fina D, Gioia V, Peluso I, Caprioli F, Stolfi C, Perfetti A, Spagnoli LG, Palmieri G, MacDonald TT and Monteleone G: Protease-activated receptor-2 activation in gastric cancer cells promotes epidermal growth factor trans-activation and proliferation. Am J Pathol 169: 268-278, 2006. 